\title{
MARINE WATER EFFECT ON COMPRESSIVE STRENGTH OF CONCRETE: A CASE STUDY OF ESCRAVOS AREA OF NIGERIAN DELTA
}

\author{
S. 0. Osuji ${ }^{1}$ and E. Nwankwo ${ }^{2}$ \\ 1,2 Department of Civil Engineering, University of Benin, P. M. B. 1154, Benin City, Edo State. Nigeria \\ E-mail Addresses:15ylvester.osuji@uniben.edu2 nwankwoebuka@yahoo.co.uk
}

\begin{abstract}
This paper examines the effect of seawater found the Excravos area of the Nigerian delta in concrete production. It is well-known that the use of seawater for mixing concrete does not appreciably reduce the strength and other properties of concrete but may lead to corrosion of reinforcement in some certain cases. Seawater obtained from Excravos area of the Niger Delta was analysed and the compressive strength of concrete produced and cured with it was obtained from the laboratory. Concrete cubes cast and cured with seawater were observed to have a higher strength at 28 days i.e. about 115\% when compared with concrete cast with fresh water. Increase in concentration of seawater used in preparation of cement paste lowers the setting time: initial and final setting time. It is subsequently recommended that the use of seawater for concrete casting and curing should not be rejected or turned down. However, in the case of reinforced concrete, it is recommended that reinforcement be prevented from corrosion by using stainless steels where available and corrosion inhibitors. However, long-term effect of seawater concentration on properties of concrete such as creep and durability were not investigated in this work.
\end{abstract}

\section{Keywords:_Compressive Strength, Aggregate, Control Test, Setting Time, Consistency}

\section{INTRODUCTION}

The primary chemical constituents of seawater are the ions of chloride, sodium, magnesium, calcium and potassium [1]. The concentration of major salt constituent of seawater is given in percentage such as $78 \% \mathrm{NaCl}, 10.5 \% \mathrm{MgCl}_{2}, 5 \% \mathrm{MgSO}_{4}, 3.9 \% \mathrm{SO}_{4}, 2.3 \%$ $\mathrm{K}_{2} \mathrm{SO}_{4}$ and $0.3 \% \mathrm{KBr}$ [3]. It is evident from above that sodium chloride is by far the predominant salt component of seawater. $\mathrm{NaCl}$ and $\mathrm{MgCl}_{2}$ are a total $88.5 \%$ of the entire salt content [4].

Alkali - aggregate reaction is a chemical reaction between certain types of aggregates and hydroxyl ions $(\mathrm{OH}-)$ associated with Alkalis in the cement or concrete $[1,2]$. Usually, the alkali comes from the Portland cement but they may also come from other ingredients in the concrete i.e. seawater. Under some conditions, the reaction may result in damaging expansion and cracking of the concrete [2].

Cracking facilitate the entry of de-icing salt solution that may cause corrosion of the reinforcing steel, thereby accelerating deterioration and weakening a structure. Cracking in concrete under seawater concrete consist of Alkali - aggregate reaction, Alkali- silica reaction and Alkali-carbonate reactions which react with Alkali in the cement. Some of the aggregate contain reactant silica which also reacts with alkali present in cement i.e. sodium oxide $\left(\mathrm{Na}_{2} \mathrm{O}\right)$ and potassium oxide $\left(\mathrm{K}_{2} \mathrm{O}\right)$. Shetty [5] reported that failure of concrete structure like pavement, piers and sea walls could be attributed to the alkali-aggregate reaction. He also stated that certain types of reactive aggregates are responsible for promoting alkaliaggregate reaction. The types of rocks which contain reactive constituents include andesite, rhyolites, siliceous limestone and certain types of sandstone. The reactive constituents may be in the form of opals, cherts, chalcetory, volcanic glass and zeolites. The reaction starts with attack on the reactive siliceous alkaline minerals in the aggregate by the hydroxide derived from the alkalis in cement or concrete. As a result, the alkali- silicate gels of results in unlimited swelling which results in disruptions of concrete with the spreading of pattern cracks and eventual failure of the concrete structure. Neville [1] reported that seawater has a total salinity of about 3.5 percent (78 percent of the dissolved solids being $\mathrm{NaCl}$ and 15 
percent $\mathrm{MgCl}_{2}$ and $\mathrm{MgSO}_{4}$ ) and produces a slightly higher early strength but a lower long term strength. He also noted that $\mathrm{PH}$ of seawater varies between 7.5 and 8.4 [1]. Seawater also contains some amount of $\mathrm{CO}_{2}$.

Large numbers of concrete structures are exposed to seawater either directly or indirectly. For several reasons, effect of seawater on concrete deserves special attention. Coastal and offshore structures are exposed to simultaneous action of a number of physical and chemical deterioration processes. The concrete in seawater is subjected to chloride induced corrosion of steel, freezing and thawing, salt weathering, abrasion by sand held in water and other bodies [5].

Research on the use of seawater in the production of concrete is practically scanty in literature due to the concerns on the use of seawater in construction. Interestingly, some researchers have argued that with use of special cements such as BFS (as against OPC), corrosion resistant reinforcements and inhibitors sea water can be satisfactorily used in concrete production [6-11]. However, in some communities where seawater abound, it is virtual impossible to produce concrete without seawater. This necessitates this work.

\section{DESIGN OF CONCRETE MIX}

The concrete materials which will be used for the purpose of this work include cement (manufactured in accordance with the requirement of BS 12:1996 [12]), normal aggregates and mixing water. The choice and preparation method for these materials are discussed in subsequent sections.

The normal aggregates that will be used for the purpose of this work, i.e. coarse and fine aggregates. The method of preparation of those aggregates prior to specimen preparation also described. The particular size distribution analysis is carried out on the coarse aggregates in accordance with the recommendation of BS: 812: Part 2:1995 [13]. The maximum size of aggregate used for the purpose of this work is $20 \mathrm{~mm}(3 / 4 \mathrm{in})$. In order to determine the initial and final setting times of standard cement paste the Ordinary Portland Cement paste, which produces the desired consistency, will be used.

\subsection{Concrete Mix Design Process and Trial Mix Procedure}

Concrete mix design can be defined as the process of selecting suitable ingredients of concrete and determine their relative quantities for the purpose of producing an economical concrete which has certain minimum properties. The mix design process form the basis for a trial mix which the properties are assessed so that the design may be modified accordingly.

The concrete mix design process which will be adopted herein is the method based on the type and quality of material and method will be subdivided into stages as recommended in BS 4550: Part 3 [14]. Four grades of concrete mix were designed, these includes grades $40,35,30$ and 25 at restricted water cement ratio $0.45,0.5,0.55$, and 0.6 .

\subsection{Effect of Seawater on the Compressive Strength of Concrete Mix}

The result of the Tables 1 show that there is an appreciable strength increment in cubes cast with seawater and cured with seawater (SS); cubes cast with seawater and cured with fresh water (SF) and all cubes cast with fresh water and cured with seawater (FS) when compare with the cube cast with fresh water and cured with fresh water (FF) which is the control test. At 7 days of curing it was observed that concrete cast with seawater and cured with seawater attained strength of about $80 \%$ of the 28 days compressive strength of the control test (FF). So at 28 days, SS (cubes cast with seawater and cured with seawater) has attained strength of about $114 \%$ of 28days compressive strength of control test (FF).

This further suggested that curing concrete with seawater has tendency or effect of increasing the strength of the cubes. The reason behind an increment in concrete compressive strength at 28days is still not easy to explain.

From Table 1, it can be observed that the rate of the strength gain in control test FF is slow, as compared with the SS test, which at 7 days has attained $64.67 \%$ of its final compressive strength. At 14 days all the tests still recorded an increase in strength. The rate of the increase in SS, SF, FS test is higher than that of FF test. At 21 days the rate of strength gained was still increasing proportionally as compared with the control test. At 28 days, the rate of strength gain is still increasing in all the tests. The control also recorded its maximum strength at 28 days. Although the compressive strengths of SS test was higher than that of the control test (FF) at 28 days. Another point worthy of note is the magnitude of the strength gain in the SS and SF tests at 28 days and the fact that the strength appear to be still increasing. There are clearly some complex chemical mechanisms involved here. 


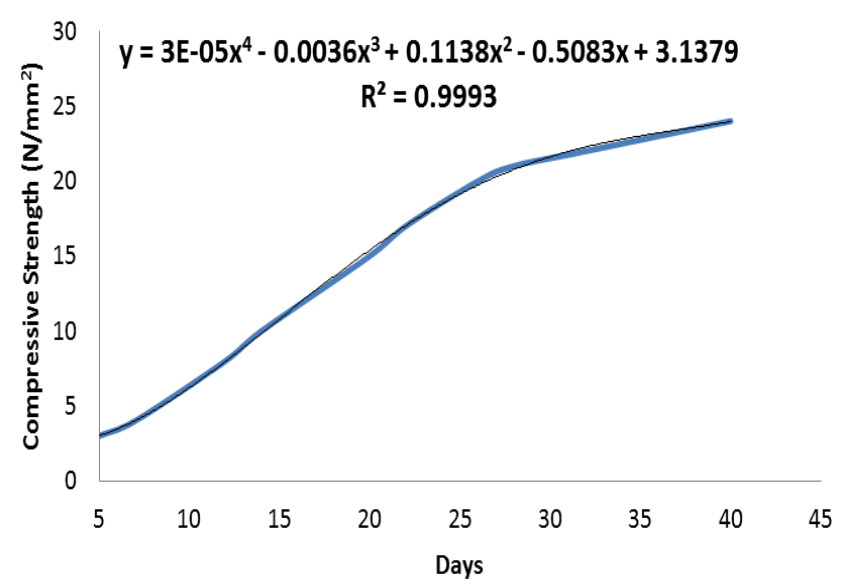

Figure 1: Mathematical relationship representing rate of development of strength for SS concrete

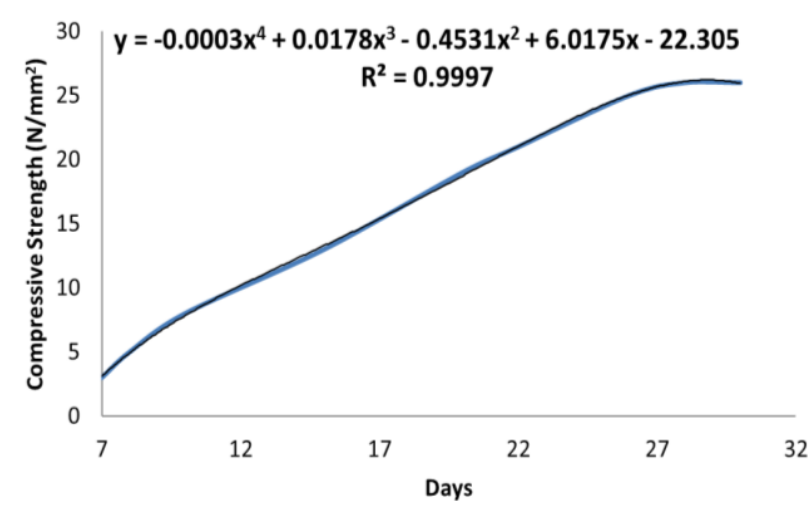

Figure 3: Mathematical relationship representing rate of development of strength for FS concrete

Table 1: Summary of Concrete Cube Crushing Strength

Cube identification

Concrete cube crushing strength

\begin{tabular}{ccccc} 
identification & \multicolumn{4}{c}{$\left(\mathrm{N} / \mathrm{mm}^{2}\right)$} \\
\hline & 7days & 14days & 21days & 28days \\
FF & 15.24 & 20.88 & 22.81 & 25.01 \\
SS & 18.62 & 23.56 & 25.64 & 28.79 \\
FS & 16.01 & 21.18 & 23.06 & 26.16 \\
SF & 16.79 & 22.51 & 24.22 & 27.37 \\
\hline
\end{tabular}

NOTE: FF = concrete cast with fresh water and cure with fresh water; SS = concrete cast with seawater and cure with seawater; FS = concrete cast with fresh water and cure with seawater; SF = concrete cast with seawater and cured with fresh water

The rate of strength development for SS, FF, FS and SF concrete can be represented in an analytical form as shown in Equation (1). Using error minimisation, as presented in Equations (2), we can solve for the constant $A_{1}, \mathrm{~A}_{2}, \mathrm{~A}_{3}, \mathrm{~A}_{4}, \mathrm{~A}_{5}$ and $\mathrm{A}_{6}$ in Equation (1).

$$
\begin{gathered}
y=A_{1} x^{4}+A_{2} x+A_{3} x^{3}+A_{4} x^{2}+A_{5} x \\
+A_{6}
\end{gathered}
$$

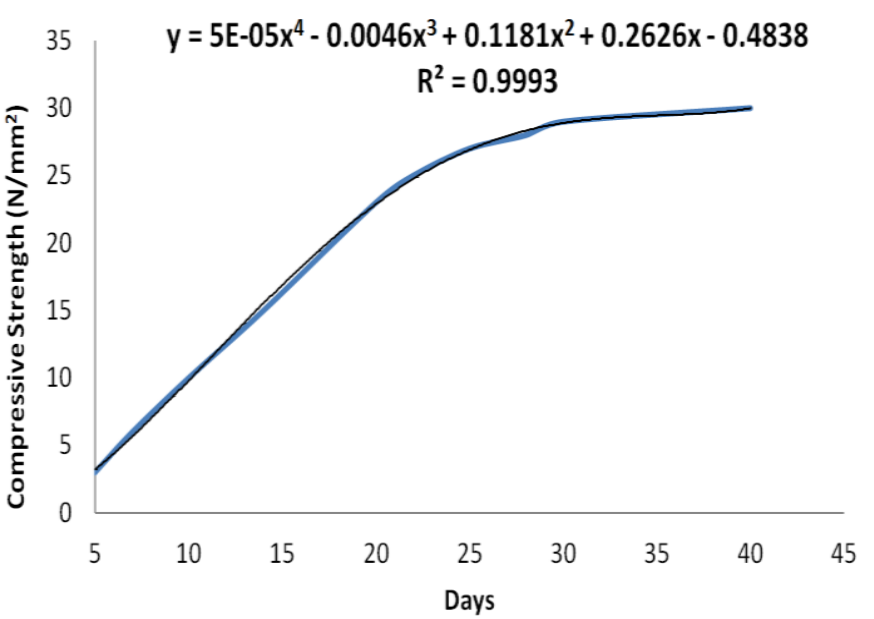

Figure 2: Mathematical relationship representing rate of development of strength for FF concrete

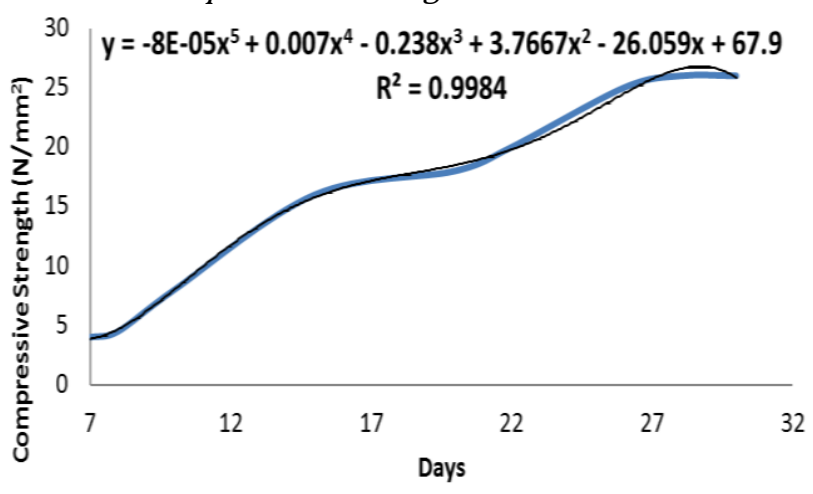

Figure 4: Mathematical relationship representing rate of development of strength for SF concrete

$$
\begin{aligned}
E=\text { error }= & \sum_{i}^{n}\left(w_{i}-A_{1} t_{i}^{4}-A_{2} t_{i}^{3}-A_{3} x_{i}^{2}\right. \\
& \left.-A_{4} t_{i}-A_{5} t_{i}-A_{6}\right)^{2}
\end{aligned}
$$

Figures 1-4 show the equation developed equations of the rate of strength formation for the various concretes and the value $R$ and $R^{2}$ values which represent the correlation coefficient and coefficient of determination respectively.

\section{EFFECT OF SEAWATER ON THE SETTING TIME OF CEMENT PASTE}

From Table 2, it can be seen that the value of the setting times of Ordinary Portland cement paste of standard consistency increases with fresh water and decreases with seawater. It is observe that the initial and final setting times of ordinary Portland cement paste increases with fresh water while the initial and final setting time decreases with seawater. This was due to the crystallization that takes place at the point of evaporation of water which has a substantial reduction in the initial and final setting time of cement paste $[1,2]$. 
Shetty [5] also reported that sulphate attack denote an increase in the volume of cement paste in mortar due to the chemical action between the products of hydration of cement and solution containing sulphates.

Experiment were carried out to determine the percentage of cement (Portland) that is, water which make the plunge needle to penetrate $33-35 \mathrm{~mm}$ when released otherwise known as consistency test. The value of consistency test is further used to determine the setting time of cement: initial and final setting time.

Table 2: Result of Cement Setting time.

\begin{tabular}{llll}
\hline Water sample used for & \multicolumn{2}{l}{ Set time (min) } \\
\cline { 2 - 3 } cement paste preparation & Initial & Final \\
\hline Fresh water & 148 & 205 \\
Sea water & 106 & 128 \\
\hline
\end{tabular}

Table 3 shows the results of the chemical analysis carried out on seawater with a view to determine the percentage by mass of compounds: $\mathrm{NaCl}, \mathrm{MgCl}_{2}, \mathrm{CaSO}_{4}$, $\mathrm{KBr}, \mathrm{K}_{2} \mathrm{SO}_{4}$ and $\mathrm{MgSO}_{4}$ dissolved in it. Each sample was measured and analysed using a flame photometric (Spectronics 20 Geneys). The result from the laboratory test gave salt component of seawater from Escravos River to be: $28.93 \% \mathrm{NaCl}, 18.56 \% \mathrm{MgCl}_{2}$, $0.54 \% \mathrm{CaSO}_{4}, 2.37 \% \mathrm{~K}_{2} \mathrm{SO}_{4}, 2.01 \% \mathrm{KBr}$ and $0.49 \%$ $\mathrm{MgSO}_{4}$

\section{Table 3: Dissolved Compound in Excravos Seawater}

\begin{tabular}{cc}
\hline Compound & \% composition by mass \\
\hline $\mathrm{MgCl}_{2}$ & 18.56 \\
$\mathrm{NaCl}_{\mathrm{CaSo}_{4}}$ & 28.93 \\
$\mathrm{~K}_{2} \mathrm{SO}_{4}$ & 0.54 \\
$\mathrm{KBr}$ & 2.37 \\
$\mathrm{MgSO}_{4}$ & 2.01 \\
Others & 0.49 \\
\end{tabular}

\section{Conclusion}

Based on the results of this experimental investigation the following conclusion can be drawn:

a) Concrete cubes cast with seawater and cured with seawater (SS) were observed to have a higher strength at 28days -about $115 \%$ when compared with control (FF).

b) Increase in concentration of seawater used for concrete mixes increases the 28 days strength of the concrete when compared with control (FF) vice-visa, irrespective of the curing medium adopted. c) Concrete cast with seawater and cured with fresh water had a higher strength at 28 days - about $110 \%$ when compared with control (FF) test.

d) The strength increment of concrete cured with seawater was between $105 \%$ to $115 \%$ the strengths of concrete cured with fresh water at 28 days.

e) Increase in concentration of seawater used in preparation of cement paste lowers the setting time i.e. initial and final setting time.

\subsection{Recommendation}

For a fuller understanding of the effect of seawater on concrete properties, further research in this area is advised. However, in line with the recommendations of Otsuka [6], the following recommendations are advised when using seawater in the production of concrete:

a) In the case of reinforced concrete, the reinforcement should be prevented from corrosion by painting or coating it with cement slurring mix with fresh water. And also the concrete mix should be dense and a cover of $75 \mathrm{~mm}$ should be provided. Or, the use of corrosion resistant reinforcements such as stainless steel should be adopted

b) Long term effect of seawater concentration on properties of concrete such as creep and durability need to be investigated. However, in performance based design, if the performance of concrete cast with seawater can be guaranteed during the life of the structure, the structure is deemed satisfactory.

The use of seawater for making and curing concrete made with Ordinary Portland Cement may be necessitated on site where portable fresh water is not available. However, the results obtained in the work should be used especially in the Escravos area of the Nigerian delta.

\section{REFERENCES}

[1] Neville, A.M. 'Properties of Concrete', Pitman Publishing Limited, London, pp. 167 - 178, 1975

[2] Neville, A.M. and Brooks J.J. 'Concrete Technology', Longman Group UK Limited, pp. 147 - 175, 1993

[3] Swamy, R.N. 'The Alkali - Silica Reaction in the Concrete', $1^{\text {st }}$ edition, CRC Press, pp. $2-47,1991$

[4] Bela M.F. 'Properties of Seawater', U.S. Dept. of the Interior, Office of Saline Water, pp. 766 - 771, 1989 
[5] Shetty M. S. 'Concrete Technology (Theory \& Practice)', S. Chand, 2005

[6] Otsuka, N. 'Possibility of Sea water as Mixing Water in Concrete', 36th Conference on Our World in Concrete \& Structures, Singapore, August 14-16, 2011.

[7] Mbadike, E.M and Elinwa, A.U. 'Effect of Salt Water in the Production of Concrete', Nigerian Journal of Technology, Volume 30, No 2, 2011.

[8] Silwinski, E.J. and Rawlins, 'High workability of Concrete mixes', The Civil Engineering, pp. 25 - 29 and March, 1981

[9] Osuji, S.O. 'Lecture Notes on Construction Material and Technology', Civil/Structural Dept., UNIBEN, 2003.
[10] Moinul Islam, M.D. 'Strengths Behaviour of concrete using slag with cement in seawater environment', Journal of Civil Engineering pp. 131, 2010.

[11] Fala M. W. 'Effect of seawater for mixing and curing on structural concrete', The IES Journal Part A: Civil and Structural Engineering, Vol. 3 No 4, 2010

[12] British Standard Institution, BS 12, Specification for Ordinary and Rapid Hardening Portland cement, 1996.

[13] British Standard Institution, BS 812: Part 2, A Method for Determination of Particle size distribution, 1995

[14] British Standard Institution, BS 4550, and Part 3, Methods of testing cement. Physical tests. Tests for setting times, 1978. 